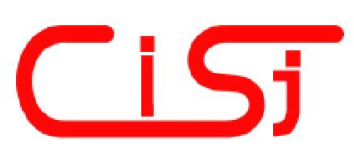

\title{
SEAMLESS AND SECURE INTEGRATION OF SOCIALMEDIA, E-PORTFOLIO AND ALUMN SERVICES INTO UNIVERSITY INFORMATION ARCHITECTURE
}

\author{
Ontje Helmich, Michael A. Herzog, Christian Neumann
}

\begin{abstract}
Magdeburg-Stendal University of Applied Sciences, Breitscheidstraße 2, Magdeburg 39114, Germany, [ontje.helmich, michael.herzog, christian.neumann]@hs-magdeburg.de, www.hs-magdeburg.de
\end{abstract}

\begin{abstract}
This document describes the concept and prototype for an "assembling" IT intergration portal to be used in higher education. Through the use of profiles, good usability and display of concentrated information students should be bound to the portal and university throughout their studies and their life.

The proposed solution, to use Elgg as an information portal and social media platform, bridges the gap between the closed nature of university IT infrastructure and user-friendly, communication enhancing advancements of state-of-theart web applications. Copyright $\mathbb{C}$ Research Institute for Intelligent Computer Systems, 2014. All rights reserved.
\end{abstract}

Keywords: social media; customized sites; university information architecture; HCI; interface design; Elgg; mashup; widget; single sign on; database exchange; alumni; e-portfolio; lifelong relation; serviceoriented architecture; Web service.

\section{INTRODUCTION AND GAP}

IT systems in higher education still offer a great potential for improvement in information quality for their users. Vital information concerning students lifes are distributed among different systems: Grades, timetables, course registrations, return dates for lend books from the library, e-mail, news, calendars or course-relevant exchange of information are not only managed in different systems, but also buried deep inside multi-step processes. The different systems all come with their own concepts of operation and login. A fast overview of important data is thereby difficult to get for their users.

At this point, a great potential is lost. Interesting insights, which could be extracted from combination of information, are not generated. Sought after interdisciplinary connections inside the student body are restrained, as contact information is hard to find even though every student owns a university email account and course participant lists are available inside the data structure.

Furthermore, current systems ignore both the locational context as well as the heterogeneous user group.

As a result most students use external social networks and exchanges information there bypassing potentially interested university parties. This finding puts university in front of multiple problems: Reasonable extensions of content on external platforms can be legally and organizationally problematic. Allocation of information on external platforms circumvents bonding to university, as users start to bond to these external platforms instead of the university.

Framework conditions, terms of use, continuity and development of external platforms cannotbe influenced by the university. The lack of resources from the university would be invested into a commercial provider, who is possible to vanish, vaporizing invested data and capital.

Last but not least the current situation opposes the paradigm of forming a lifelong partnership with university that is especially anchored in AngloAmerican universities. Often students are cut off from their information immediately with exmatriculation by deactivating their accounts, which is not only problematic regarding informational self-determination. Most of all, university immediately loses the communication channel built for yearswith former students.

\section{RESEARCH METHODOLOGY}

For the demonstrated approachin this paper Social Media Systems were elaborated. They provide a wide variety of functions for collaboration and interaction. That covers explicit as well as implicit knowledge distribution und knowledge 
development in large organizations. Driving Social Systems in Universities provide substantial impact on academic as well as on social learning outcomes, but also on employees satisfaction and Alumni relations [1].

To face above problems the project karriereLEBEN at University of Applied Sciences Magdeburg-Stendal researched and developed an "assembling" IT integration concept. Influenced by service-oriented architecture (SOA) this approach should provide room for highly diverse IT systems and be supplemented by an information-integrating architecture, that condenses fundamental information context-sensitive and focused on targetgroups. This "assembled" distillate is offered and conjoined at a web-based platform.

Methodically the design-oriented Information Systems research process [2] was used and detailed as follows:

1. System analysis of special IT architecture and solutions [3], their comparison and generalization

2. Design-driven development of the integrational concept and associated prototypical implementation [4]

3. Evaluation in concrete application environments with relevant target groups

4. Diffusion

As central research questions the following problems were identified:

- How is it possible to integrate existing systems and data sources to create a more user-friendly approach to university IT Infrastructure?

- How to bridge the gap between a secure IT architecture, a seamless authentication and a service oriented openness and flexibility of an intranet system.

From a conceptual project perspective the following questions influenced the system design:

- How can a lifelong bonding and identification with university be reached with Social Software?

- What services encourage user activity?

- How to optimize fundraising with intranet social media software?

\section{APPROACH, TECHNOLOGIES AND APPLICATION}

The goal to reach is a so-called "one stop shop", both for the user and the organization to retrieve all information on one platform. Relevant information from diverse sources will be distilled, conditioned and presented. To offer additional functionality, information will be deep-linked directly to appropriate systems. Through the collection of information into one portal and the application of
SingleSignOn (SSO) there will be only one login for all systems. By using metadata from this login it is possible to present information target-group specific and context-sensitive.

The integration of an internal social network helps in forming a sense of exclusiveness. Additionally a role-based rights management aids in progress of studies. Beginning with enrollment the users status inside the portal rises proportionally to his progress, enabling new modules on the way.

By creating personal profiles, users can show off their interests and make it easier for others to find them. These profiles are a great benefit to both student body and CareerService. Students are allowed to present themselves within the context of university. University can verify provided information and apply its reputation to every student. CareerServices can target specific student groups for offers of internships and jobs more directly. Even inside the institution a tighter network will be formed: Research groups can find active participants, professors can advertise job opportunities and theses to a relevant audience.

\subsection{PROTOTYPE}

A prototype of the mentioned approach was built at University of Applied Sciences MagdeburgStendal and evaluated with early adopter user groups. The prototype is running on an Ubuntu 12.04 LTS host in a demilitarized zone of the universities network. It is based on Elgg [5] and a MySQL database. Elgg is an open source social networking engine, that allows anyone to build and host their own web-based social network. With help of self-developed plugins and widgets Elgg demonstrates the introduced usability concept in cooperation with a personal desktop (Fig. 1). This desktop contains a variety of widgets that are connected to the different IT systems inside the University and filter the desired information. The user is able to create his personal space and entrypoint into the different systems.

Furthermore contacts to former and current students and personnel can be established. Bulletin boards, blogs, email, chat and groups offer many forms of communication. The user profile can be extended into an advanced and feature richEPortfolio [6] that will be used as a learning, communication or research environment. This accumulated portfoliocould be used later as a public career instrument, for student job applications or as a project, practice, research and teaching demonstration. It could contain curriculum vitae, works, certificates and grades, electronically certified from the university. The web-reputation of the university also helps in making the portfolio 
visible and easy to find in search engines on the Web.

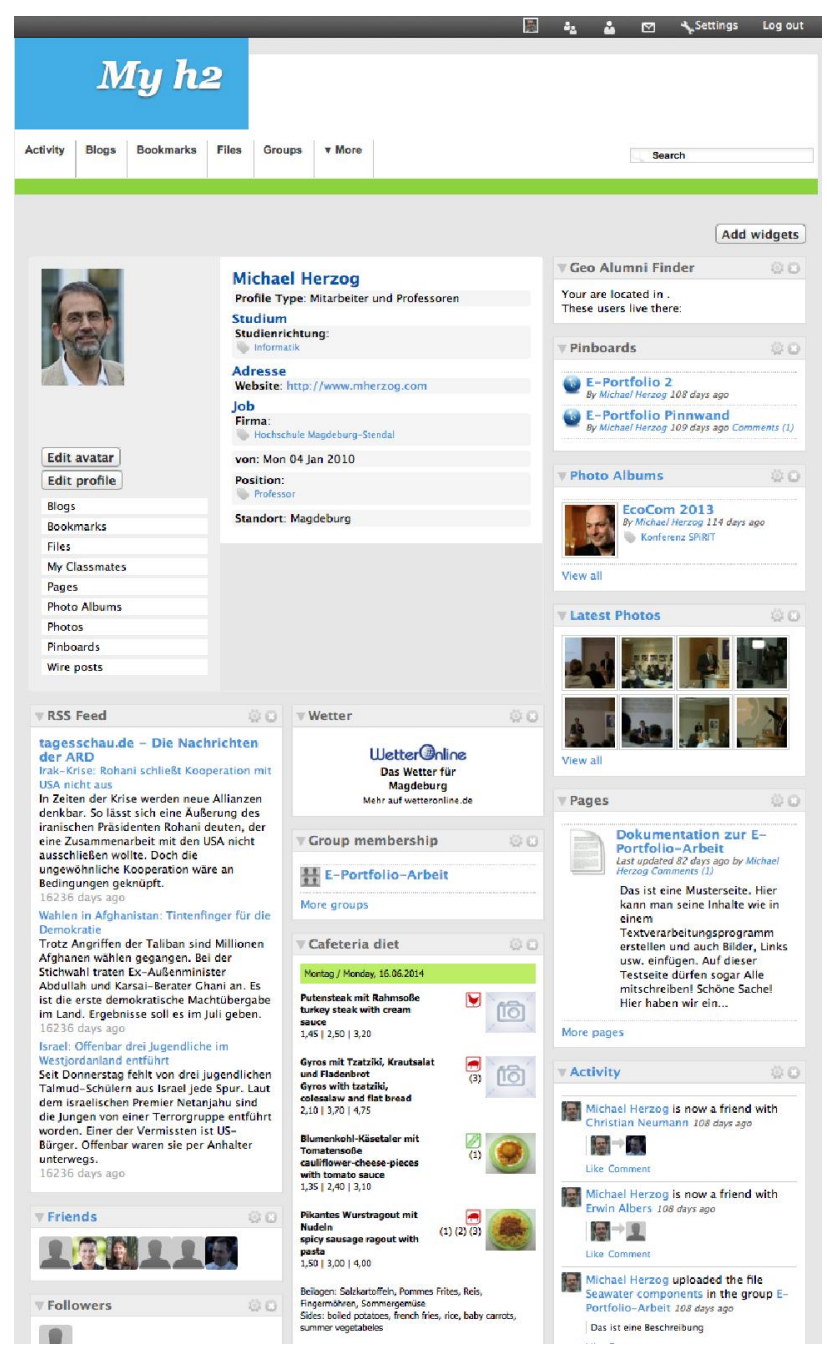

Fig. 1 - Personal desktop with user profile.

\subsection{DESIGN}

To not only technically but also visually embed the prototype into the university's infrastructure, the screen design of the prototype was adopted to match the visual design of the university website.

This harmonization also creates a more seamless experience for the users of the prototype, as they do not have to learn a new visual language and navigational approach if they are already familiar with the university's website.

The visual concept also follows the idea of a flexible mashup widget environment [7]. Every function is realized in a flexible micro window that users can move and adjust to their individual preferences. This individuality allows a seamless feeling of freedom for the user who is able toreorganize the screen, add new functions or delete unwanted widgets.Monitoring of these user preferences and function usage will allow optimization of the default system settings and improvement of widget functions.

\subsection{AUTHENTIFICATION}

To securely identify members of the university and allow non-members to sign up, the prototype utilizes a staged LDAP and database handler for registration and authentication.

The LDAP handler authenticates current members of University while the database handler authenticates non-members. Students, faculty and staff need only to use their central university account at registration, accept the terms of use and the LDAP handler will automatically import all relevant data from the central LDAP server into Elgg's user-database.

Non-members need to fill in all their user data themselves. Non-members of university are either alumni or friends, which include guests, companies or sponsors. They use a special registration form. Because the prototype does not have influence on current and future user-name policies of the university, it simply adds some characters to usernames not originating from LDAP, to safely distinct them from current or future university members.

At authentication, the prototypefirst asks the LDAP handler and only falls back to the database handler on denial. On every successful LDAP authentication all user data will be updated from the central LDAP repository. Copying the users data to our own database makes it possible to still allow access to users who signed up as members of university and have since left, even though the university's policy is to delete their LDAP account on leave. They only need to reset their password - as we never received it from LDAP - and can then login again.

\subsection{UNIVERSITY INFORMATION ARCHITECTURE}

The introduced portal could realize a smart fit into the general strategy of the university. Students are integrated into respective processes and thereby bond to university. Moreover they directly and indirectly collect information to be used by CareerServices.

In terms of usability the platform aims for simplification through reduction [8] by concentrating relevant information into one central place and thus by reducing the number of systems a user has to searchto find this information. In current SingleSignOn systems only repetitive login is prevented, but users still need to jump from system to system to find information. The platform will connect participating systems and extract information into a single place.

Furthermore, external services in which the user does currently not use the central university account 
can be incorporated into this SSO. This contrasts current applications of SingleSignOn systems, Central Authentiction Service (CAS) [9] and Shibboleth [10] at university that only allow inclusion of services using the exact same local user name.

Inside the prototype's account manager users are allowed to connect user names of external services to their local account and allow inclusion of external services user data.

Users thereby not only activate access to external systems but also decide which systems to use via SSO and what data to include into the local internal university services.

Network architecture in Fig. 2 shows the services connected to the prototype. While all accounts inside the university network use the central university account, external services of Career Center and Libraries use their own accounts. If the user wants to only read information from these systems, there is no requirement to enter account information into the account manager. The prototype directly connects to the database of these services by means of an SSL tunnel and presents query results directly to the user. For example, the user can see current job and internship listings of the Career Center right inside the prototype. The system will even preselect relevant listings using data from the users E-Portfolio.

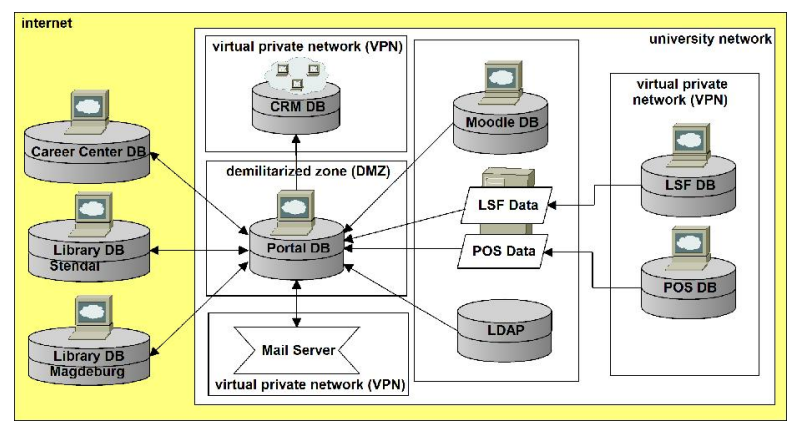

Fig. 2 - Connected services model.

The university network is split into different subnets. Being a globally accessible service, the prototype is located inside a demilitarized zone (DMZ), while the rest of the shown services are located inside the internal network. For Customer Relationship Management (CRM), LDAP, Moodle and Webmail connections are allowed via corresponding firewall rules. LSF [11], containing timetable and room allocation information and POS [12], containing grade and credit information, are inside a specially secured network without access to the prototype.

In a first version of the prototype LSF and POS databases were exported daily into read-only CSV files and provided to the prototype via a dedicated fileserver. This security barrier was introduced so that users are guaranteed to only read and never write this sensitive information. However, due to real-time interaction and data privacy protection concerns, it was changed to access the data via SOAP and webparsing.

\subsection{METHODS OF ACCESSING DATA}

To integrate data sources into the prototype the following methods are used. They are sorted from most to least feasible for use in our prototype.

\section{1) Web API}

An API provides the most useful connection to the host's data. A good API abstracts implementation specific details away from the data and thereby makes it easy to create and maintain access, as changes in the underlying storage of data can be hidden behind the API.

In many cases APIs also have good documentation, providing further assistance to the developer. In case of LSF and Moodle this is realized using the SOAP protocol.

\section{2) Direct database connection}

This type of connection is mostly used in the prototype. It enables the prototype to access all of the data on the servers in real-time. However, it has the drawback of being very implementation specific. Initially one has to understand the exact implementation and structure inside the database. This needs then to be recreated as specific database queries in one's own software and will likely break if the original database is changed by an update.

\section{3) Read-only database dumps}

This method is often seen in university IT projects. The database of interest is dumped daily onto a fileserver. At a later time, the exported data is accessed and then imported into one's own database. The reason given for this approach is that it is impossible for the reading server to write back into the original database - which is important for data that needs to be highly reliable such as grades - as it only accesses a read-only file on a different fileserver. However, the authors would like to point out that this approach opens up a new attack vector onfileservers to gain the data.

\section{4) Scraping}

As a last resort web scraping is used for information sources that do not offer any data connection. With the scraping method, HTML output of a database or webportal is analyzed and the needed information is extracted. This method has several drawbacks. First of all, it requires a lot of initial and maintenance work. Each scraper has to be custom fit to the website it is scraping from and every change on the original websites output requires a new adaption of the scraper. 
Secondly, if the data to be accessed is non-public and protected by any form of authentication this has to be reflected in the scraper - which is often non trivial to implement. In the worst case the scraper needs to emulate an actual user on a browser, which tends to need a lot of system resources and therefore does not scale nicely to a large userbase.

\subsection{ROLES}

Display of information is based on roles. Users are grouped as Students, Faculty, Staff, Alumni and Friends.

The role system prevents users from accessing information that they should not access, because roles will be granted from LDAP only. If the user authenticates his status will automatically be updated on every login.

Through the lifetime of a user his role could change: From student to alumnus or from staff to friend. This change is reflected in the desktop's appearance. For example, when a student becomes an alumni, widgets displaying the current study progress turn into GeoAlumniFinder. Alumni and friends will also be included into the ranking of top supporters and will be displayed information regarding support programs and calls for sponsors.

The staffs are informed about new alumni and friends who are not yet in the CRM system and can decide if they should be added to the CRM database.

\subsection{SOCIAL MEDIA COMPONENTS}

Social Media components should improve communication at and around campus.

Except for Webmailer and e-learning portal Moodle none of the currently connected or implemented services offer any means for communicating with other users.

However, communication in Moodle is restricted. It is impossible to directly reach fellow students without selecting the proper course first, making it virtually impossible to comfortably communicate with loose contacts.

Based on social media open source platform Elgg the prototype allows for far more ways of communication. All users are discoverable inside the system and can be added to the users friends list. The users are also kept up to date with permanent display of incoming messages and a newsfeed displaying all updates from friends.

The users have a lot of possibilities to communicate, to create and to share content: blogs, groups, messages and their own E-Portfolio.

The E-Portfolio helps users to enhance their profile. By displaying certificates from POS, LSF and Moodle students are allowed to demonstrate their performance and achievements to a broad community. These certificates can easily be combined with the student's curriculum vitae to create an interesting online profile for possible employers.

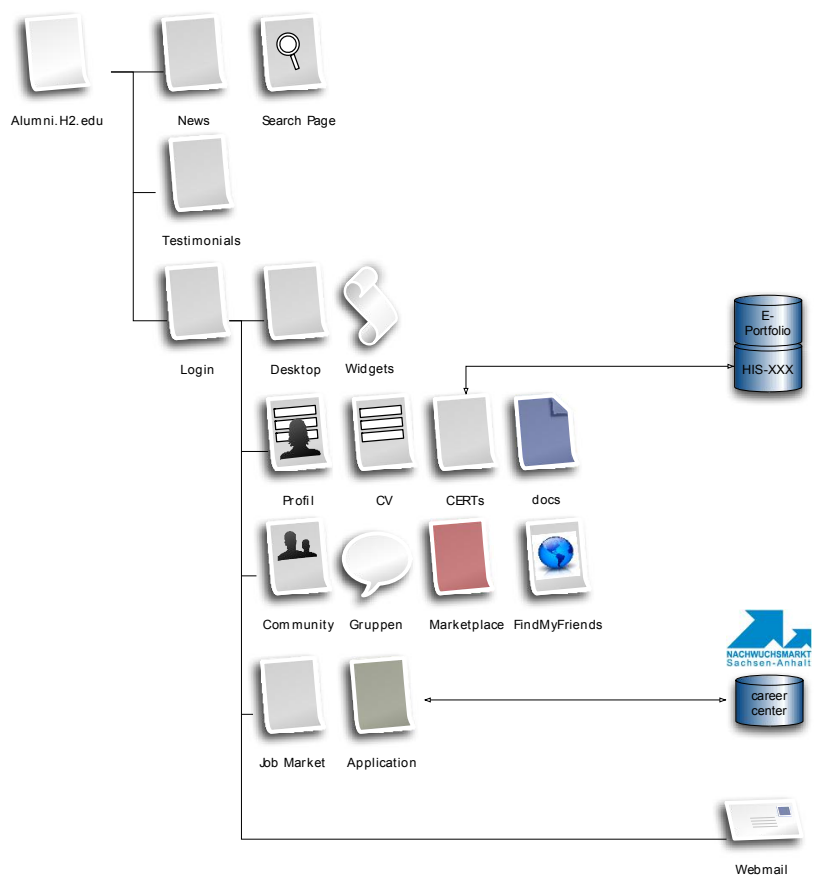

Fig. 3 - Portal navigation and database structure.

\subsection{E-PORTFOLIO}

Following guidelines from Magdeburg-Stendal University of Applied Sciences' Center for Didacticsthe prototype was extended with more E-Portfolio functionality. As described in chapter A, Elgg offers a lot of functionality to turn the user profiles into an E-Portfolio. Baumgartner's evaluation of E-Portfolio Software shows that Elgg is a good candidate to be used as such [6]. Fueled by these findings, further implementation was done to propose the usage of this prototype as the university's E-Portfolio platform. In his evaluation, Baumgartner also outlines criteria for a good EPortfolio and evaluates Elgg's fit with these. Elgg's worst performance according to his evaluation is in the field of the major category 2 "Reflecting, testing, verifying and planning", however the authors of this paper found these content based criteria to be out of scope for the current development.

In our implementation a lot of work has been done to extend the functionality in the field of "Representing and publishing" where the PinboardPlugIn offers the required features.

A more detailed description of implementation specifics can be found in I.4. 


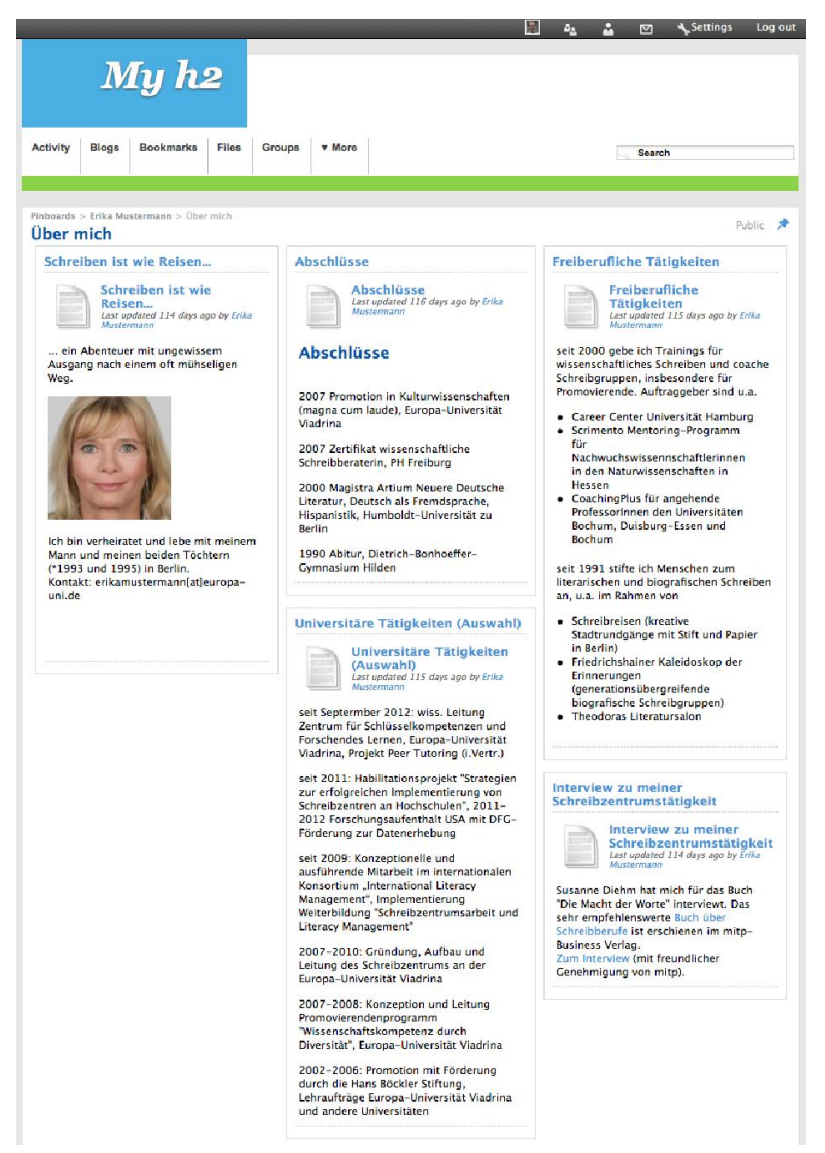

Fig. 4 - Teaching portfolio example.

\subsection{ELGG PORTAL ADAPTION}

To prevent the plugins from directly affecting the core of Elgg, all of the prototypes functionality was implemented writing, using and extending plugins for Elgg. This also helps to avoid SQL injection and XSS attacks, as by using proper plugins and coding against the Elgg API, forms and inputs are abstracted into Elgg'sInput/Actions and Views/Output concept and database queries are not directly written in SQL but use Elgg's protected methods and classes.

Currently used plugins are shown in Fig. 5. Due to the highly modularized approach of Elgg, the amount of plugins to implement the prototypes functionality is rather high. This offers great flexibility but also results in a lot of adaption work to make the plugins and theme compatible with each other.

\subsection{PLUGINMODULE DEVELOPMENT}

The following is a list of specific implementation details and used plugins, to give deeper insight into this approach and implementation (see Fig. 5).

\section{5) Backup}

The deployed community version of Elgg (1.8) got a full backup functionality with data folder and mysql dump. The scheduled backup is controlled via an Elgg handler, which gets called by the Linux utility cron. However it only works if you have a second host to backup to [13].

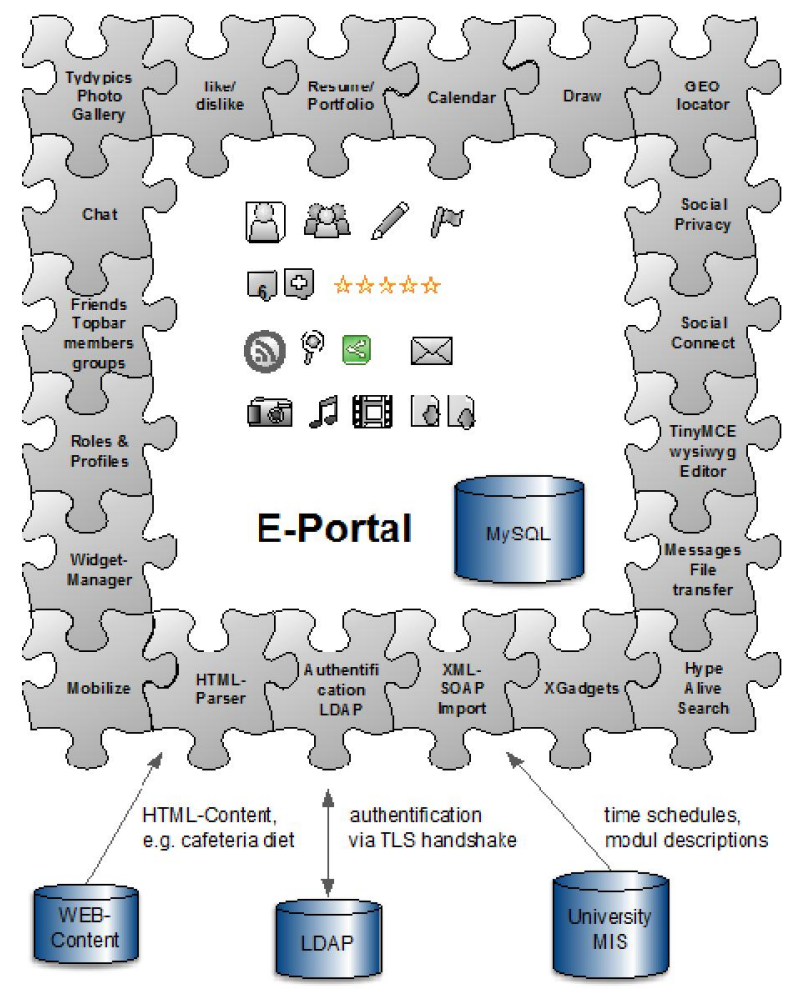

Fig. 5 - Used plugins and functionality.

Instead of this functionality a full server backup approach was implemented using the university's backup infrastructure based on TIVOLI storage manager.

6) Authentification

To allow members of university to login with their official university account, this plugin connects after an TLS handshake and via a secure connection to the OpenLDAP server of the university. At first login and a successful LDAP query, the user is asked to accept the terms of use and privacy policy. Only then his profile is created. Mapping of LDAP attributes with those of the Elgg portal is done in the plugin settings.

To assign the user role, the Profile Manager plugin [14] from the Elgg Community needs to be installed and activated as well. Without this dependency the OpenLDAPplugincan not be activated.

After registration, with each login via username or e-mail address the LDAP-attributes get updated from the LDAP server.

The OpenLDAPplugin is executed before the normal portal login method and falls back to it, so that Alumni and Friends - who do not have their account stored in university LDAP - can be authenticated with the portal's own user database. 


\section{7) Extended Registration plugin}

Alumni and Friends need to explicitly register with the portal and confirm their e-mail address via an activation link. This plugin extends the portal's registration page with a checkbox, so that users need to accept the portal's term of use and privacy policy. The plugin also implements a method to avoid username duplicates between the university's LDAP and the portal's own database, as described in II B.

\section{8) Resume and Portfolio}

In regards of the E-Portfolio, Elgg by default provides the artifacts Blogs, Bookmarks, Filestorage and the creation of own pages. Personal pages can be edited using the built-in editor and it is possible to link to one's own files. It is even possible to create sub-pages that can be easily found through a navigation structure.

With the Profile Manager an admin can include additional forms so that users can use them on their profile pages, for example course of study, address and profession.

To use these functionalities didactically for learning purposes, the PinboardPlugIn [16] was added. It allows the user to create pinboards wherein he can include all of his artifacts as widgets. These can be displayed in varying layouts and it is possible to determine precisely who can view or edit any of one's pinboards, by using Elgg's advanced roles management and custom member lists.

By using multiple pinboards it is possible to build similar structures as are found in more classical E-Portfolio systems. A structural example for an E-Portfolio from the pedagogical viewpoint is shown in Fig. 6. The prototypical implementation includes pages with up to three columns and a Blog a long side the textual content, to document progress in a chronological manner and to receive comments from other users.

$$
\begin{aligned}
& \text { Profile } \\
& \text { - My CV } \\
& \text { - Evaluation results } \\
& \text { - Dimensions } \\
& \nabla \text { My teachings and it's developments } \\
& \text { - Blog } \\
& \text { - Development targets and more } \\
& \nabla \text { Theoretic and literature work } \\
& \text { - My study accomplishments } \\
& \text { - Texts / Contents } \\
& \text { - Blog }
\end{aligned}
$$

Fig. 6 - E-Portfolio example for educational purposes - table of contents [15].

\section{9) SOAP Import}

For LSF and Moodle a SOAP-based webservice can be activated [17]. Public information such asthe schedule of lectures or the search for individuals can be queried from LSF via a SOAP-client without authentication and displayed in the portal. For nonpublic information like the user's personal schedule a SOAP-based authentification is required. The authentification request as well as the query and the result are held in an XML-structure. After an XSLTtransformation using a parser the result is displayed in the portal.

\section{0) Mobilize and Corporate Design}

The theme is realized as a plugin as well. It is possible to simply copy all CSS files and their folder structure of the core into the view structure of the plugin. These files can then be adapted to the university design. After purging the site-cache the plugin's CSS files will overload the core files.

In parallel the Mobilize Theme [18]is loaded, which automatically switches the layout to a mobile friendly view on mobile devices.

11) Digital yearbook

This plugin also requires the Profile Manager plugin from Elgg Community, into which all programsof universityhave to beentered. Inside the Profile Manager each course of study can be marked as a Tag, so that all users can be listed based on their course of study.

The Digital yearbook plugin extends this functionality by enabling an additional list grouped by year of matriculation. It can also highlight currently online users from the same year as the user, as long as he has marked his matriculation inside his profile.

\section{2) GeoAlumniFinder}

The GeoAlumniFinder provides the functionality of finding friends from the prototype whose location is close to ones own. The prototype uses afreely available country and city database from Maxmind [19] and corresponding GeoIP2 PHP API [20] to find the users location based on his IP. Afterwards the determined location is compared with the listed residence in public profiles.

\section{3) Cafeteria diet}

This plugin provides a widget with the cafeteria's current menu. As the University of Applied Sciences Magdeburg-Stendal has two locations with own cafeterias, MensaPlan captures the users location and displays only the menu of the nearest canteen. The actual menu is scraped from the canteens website and adjusted to the portal style.

\section{COMPARISON WITH OTHER APPROACHES}

\subsection{COLLEGE MOBILE APPS}

Students enjoy simpleness and flexibilityof college apps like tub2go [21]. Location based and time dependent they get news and concentrated 
information from their university. However, there is no integrated social media and it is usually not possible to communicate with classmates and alumni in a context integrated way. Also, the universities do not get detailed information about their users. They are anonymous by default and need only to authenticate for special information e.g. grade overviews. In conclusion, universities lose information for communication, marketing, and fundraising opportunities.

\subsection{FACEBOOK MOBILE APPS}

The Leuphana University of Lüneburg follows its students into the most used social media network Facebook. There, the university offers part of her study service as a Facebook app [22] to reach students. It is a good solution to spread the general news and there are also groups and user profiles. For the alumni management however the most important question is: Who guarantees that Facebook still exists in 50 years? Therefore, the Leuphana has her own portal [23] for students and alumni. This portal is specialized to create own profiles for the career center and the graduate's yearbook.

\subsection{MAHARA E-PORTFOLIO}

Mahara is a specialized online tool to create personal E-Portfolios [24]. It is currently highly regarded in the academic scene because of its connection to the moodle LMScommunity. However, most of its functionality is already implemented in Elgg [14], [16]. Furthermore our initial tests of Mahara show that Elgg offers some real advantages: A field experiment with two groups of students $(n=16, \quad n=21)$ revealed several improvements in the areas of functions, tools, access, and usability. Within a Mahara two days training with lecturers, two other field experiments with our E-Portfolio portal were conducted $(n=12$, $\mathrm{n}=6$ ). Thistest was lead by an external E-Portfolio expert of the University of Hamburg, Ivo van den Berk, in a workshop held at Magdeburg Stendal University in April 2014. Test results showed that Elgg portal 1.8. implementation with our project extensions tests better in most of the criteria evaluated than the hosted version of Mahara 1.8 as provided by "mahara.de". It prevailed in ease of use, comprehensibility, flexibility, user role concept and access, seamless integration, conflict management and overall look \& feel.

\section{OUTLOOK / PERSPECTIVES}

\subsection{CONCLUSIONS}

The first iteration of the prototype was well received within the group of staff and students it has been tested with. The most valued features were the easy access to information in one place and easy means of communication. Informal interviews suggested that these two features could lead to increased user activity and that social communication features could lead to prolonged bonding to the system and therefore to the university.

Furthermore, the case of extending the prototype with E-Portfolio functionality has shown that the original approach of creating a modular in-house development has opened up the possibility to create additional benefits within the system that were not inside the scope of the original design and that this approach is therefore a fruitful one.

\subsection{FUTURE WORK}

The integration of different university IT systems into the prototype and before mentioned user tests have demonstrated how difficult and at the same time how crucial this integration is for the user experience. This barrier could be lowered by recent plans to update current university LSF and POS systems to the new and integrated HISinOne solution, however - as there currently is no standard to deal with these kinds of information - it is also possible that the change will generate more adaption specific work.

In conclusion, integration of existing systems and data sources of university IT infrastructure into userfriendly applications seem feasible by introducing a web-facing portal as an aggregator and gateway into internal systems.

\section{ACKNOWLEDGMENT}

The authors wish to thank Jan Mugele and Norbert Doktor, who inspirated and helped to realize project karriereLEBEN. Another thank goes to jury members of contest "Wettbewerb 2012 Karrierewege" from "HochschulinitiativeNeueBundesländer". Their donated award made it possible to start and finance the project and to get substantial support from universities administration.

We also thank our colleague Artur Borodatyy, who supported us in developing the prototype, Ulrike Schmalreck and Stefanie Suhr for their engagement in content creation, esp. done on testimonials.

This article is an extension of a paper that has been previously presented by the authors at IDAACS'2013 [25].

\section{REFERENCES}

[1] Zeng, Lily, Holly Hall, and Mary Jackson Pitts, Cultivating a community of learners: The potential challenges of social media in Higher 
Education, in H. S. Noor Al-Deen \& J. A. Hendricks (Eds.), Social media usage and impact, United Kingdom: Lexington Books, 2012, pp. 111-128.

[2] H. Österle, J. Becker, U. Frank, T. Hess, D. Karagiannis, H. Krcmar, P. Loos, P. Mertens, A. Oberweis and E. J. Sinz, Memorandum on design-oriented information systems research, European Journal of Information Systems, (20) (2011), pp. 7-10. doi:10.1057/ejis.2010.55.

[3] H. Krallmann, M. Schönherr, M. Trier, Systemanalyse im Unternehmen Prozessorientierte Methoden der Wirtschaftsinformatik. Oldenbourg Wissenschaftsverlag, 5. Auflage 2007. (in Germany)

[4] J. R. Venable, Design Science Research Post Hevner et al, Criteria, Standards, Guidelines, and Expectations, in Global Perspectives on Design Science Research, Lecture Notes in Computer Science, Vol. 6105, Springer, Berlin Heidelberg, 2010, pp. 109-123.

[5] Elgg - Open Source Social Networking Engine, URL: http://www.elgg.org.

[6] K. Himpsl, P. Baumgartner, Evaluation of Eportfolio software, International Journal of Emerging Technologies in Learning, (4) 1 (2009) http://online-journals.org/index.php/ijet/article/view $/ 831 / 0$

[7] J. Yu, B. Benatallah, F. Casati, F. Daniel, Understanding mashup development, IEEE Internet Computing, (12) 5 (2008), pp. 44-52.

[8] J. Maeda, The Laws of Simplicity, The MIT Press, 2006.

[9] Central Authentication Service (CAS), URL: http://www.jasig.org/cas, accessed on 31.05.2013.

[10] Shibboleth, URL: http://shibboleth.net, accessed on 31.05.2013.

[11] LSF, URL: http://www.his.de/abt1/ab10, accessed on 31.05.2013. (in German).

[12] POS, URL: http://www.his.de/abt1/ab02, accessed on 31.05.2013. (in German).

[13] S. Kamolov, Back up tool for Elgg 1.8, URL: http:/community.Elgg.org/plugins/1329896/1.1 /backup-tool, accessed on 13.04.2014.

[14] J. Dalsem, Profile manager for Elgg 1.8, URL: http://community.Elgg.org/plugins/1176403/1.8 /au-sets-pinboards, accessed on 13.04.2014.

[15] OLAT - Online Learning and Training, University of Hamburg, URL: https://www.olat.uni-hamburg.de/olat/auth/1:1: 0:0:0/, accessed on 07.08.2013.

[16] M. Beckert, AU Sets (Pinboards) for Elgg 1.8, URL: http://community.Elgg.org/plugins/ 1176403/1.8/au-sets-pinboards, accessed on 13.04.2014.
[17] H. Gossen, A. Roth, Die Datenintegration zwischen HIS-LSF und universitären Lern- und Arbeitsplattformen - Ein Praxisbericht aus dem Locomotion Projekt, URL: https://wiwi.unipaderborn.de/fileadmin/lehrstuehle/department3/wiwi-dep-3-1s-5/Forschung/Publikationen/ gossen_roth_die_datenintegration_zwischenhis -lsf_und universitaeren_lern-_und arbeitsplatt formen 2007 .pdf accessed on 13.04.2014. (in German).

[18] P. Jensen, Mobilize - Mobile plugin for Elgg 1.8, URL: http:/community.Elgg.org/plugins/ 847027/2012.07.18/mobilize-mobile-plugin, accessed on 13.04.2014.

[19] Maxmind, GeoLite2 Free Databases, URL: http://dev.maxmind.com/geoip/geoip2/geolite2/ , accessed 13.04.2014.

[20] Maxmind, GeoIP2 PHP API, URL: http://dev.maxmind.com/geoip/geoip2/downloa dable/\#MaxMind APIs, accessed on 13.04.2014.

[21] Technische Universität Berlin, Web App tub2go, URL: http://tub2go.tu-berlin.de, accessed on 01.03.2013. (in German).

[22] Leuphana Universität Lüneburg, FacebookApp, URL: https://www.facebook.com/ Leuphana, accessed on 01.03.2013. (in German).

[23] Leuphana Universität Lüneburg, Alumni Portal, URL: http://www.leuphana.de/alumniportal. $\mathrm{html}$, accessed on 01.03.2013. (in German).

[24] Mahara - ePortfolio software, URL: http://mahara.de/, accessed on 13.04.2014. (in German).

[25] C. Neumann, O. Helmich, M. A. Herzog, Integration of a social media plattform into university information architecture, Proceedings of the $7^{\text {th }}$ IEEE International Confernce on Intelligent Data Acquisition and Advanced Computing Systems; Technology and Applications, (IDDACS'2013), Berlin, 12-14 September 2013, pp. 193-196. URL: $\mathrm{http} / / /$ ieeexplore.ieee. org/xpl/articleDetails.jsp? arnumber $=6662669$, accessed on 13.04.2014.

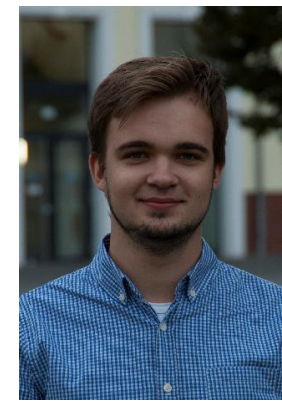

Ontje Helmich is a scientist at research group SPIRIT of Magdeburg-Stendal University, where he is currently working as part of ROSI-3D project, improving RFID localization via $3 D$ simulation. Ontje holds a Bachelor in Industrial Design and is a Masters student in the Interaction Design Master program at Magdeburg-Stendal University. 


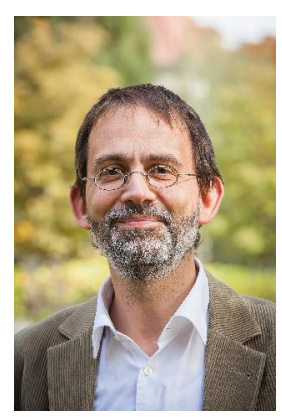

Michael

professor

A. Herzog is full for Business Management and IT at Magdeburg-Stendal University. His research is concerned with mobile systems, RFIDtechnology, sustainability in ICT, and e-learning. $\mathrm{He}$ founded several international operating IT-enterprises concerning media technology and software development. Michael holds a PhD in information systems and master's degree in computer science from Technische

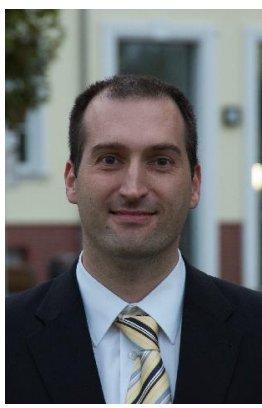

Christian Neumann is a software engineer at Center of Information and Communication at Magdeburg-Stendal University. His journal contribution was developed as former assistant at research group SPiRIT, where he was project manager and software developer of karriereLEBEN project. Christian holds a masters degree in Computer Science from Otto-von-Guericke University Magdeburg. Universitat Berlin. 